\title{
PROCESSO DE COOPERAÇÃO COMO FERRAMENTA DE ORGANIZAÇÃO ENTRE GRUPOS ATINGIDOS POR GRANDES EMPREENDIMENTOS: O CASO DO MINERODUTO DA FERROUS NA MICRORREGIÃO DE VIÇOSA - MG
}

\author{
COOPERATION PROCESS AS A TOOL OF \\ ORGANIZATION BETWEEN GROUPS AFFECTED BY \\ LARGE VENTURES: THE CASE OF THE FERROUS \\ PIPELINE IN VIÇOSA - MG
}

\author{
Dayane Rouse Neves Sousa \\ Universidade Federal de Viçosa - Viçosa - MG - Brasil \\ Marcelo Leles Romarco de Oliveira \\ Universidade Federal de Viçosa - Viçosa - MG - Brasil
}

\begin{abstract}
Resumo: Este estudo analisou como ocorre o processo de cooperação entre grupos atingidos por grandes empreendimentos de infraestrutura em um cenário marcado por conflitos ambientais. Neste caso, referenciado pela expectativa de instalação do mineroduto da Ferrous, na microrregião de Viçosa, localizada na Zona da Mata de Minas Gerais. Metodologicamente, utilizou-se de análise documental; entrevistas semiestruturadas e de acompanhamento às reuniões das comunidades atingidas e da Campanha Pelas Águas e Contra o Mineroduto da Ferrous, às audiências públicas e às manifestações realizadas por atores contrários ao empreendimento. As ferramentas de organização utilizadas pelos grupos atingidos foram as reuniões, a constituição da Campanha pelas Águas e Contra o Mineroduto da Ferrous e o processo de constituição da Associação dos Atingidos pelo Mineroduto da Ferrous. Portanto, esses atores sociais utilizaram a cooperação como ferramenta para se organizar, tendo como principal objetivo impedir a construção do mineroduto. Contudo, conscientes da dificuldade de se alcançar tal intento, os atingidos querem que alguns impactos sejam eliminados. Para tanto, eles reivindicam que o valor das indenizações passe por uma reavaliação, bem como, que o mineroduto não passe nas nascentes, mudando o seu trajeto.
\end{abstract}

Palavras-chave: Cooperação. Conflito. Mineroduto. 


\begin{abstract}
This study aimed to analyze how is the process of cooperation between groups affected by large infrastructure projects in a scenario marked by environmental conflicts in this case referenced by the installation of the pipeline Ferrous in microViçosa-MG, located in the Zona da Mata of Minas Gerais. Methodologically we used document analysis, interviews and semi-structured follow-up to meetings of the affected communities and the Campaign Against Through Water and Pipeline Ferrous, at public hearings and protests by actors opposed to the project. The tools of organization groups achieved the meetings were used, the formation of the Campaign Against Water and Pipeline of Ferrous and the process of constitution of the Association of those Affected by Pipeline Ferrous. Therefore, these social actors cooperation as a tool used to organize them because the common goal is firstly that the pipeline is not built. But how difficult this is to happen, those affected want some impacts are eliminated, among them: the amount of damages to be reassessed and consequently increase the value, and that the pipeline does not pass in the springs, changing its path.
\end{abstract}

Keywords: Cooperation. Conflict. Pipeline 


\section{INTRODUÇÃO}

Este estudo analisa como se dá o processo de cooperação entre grandes grupos atingidos por empreendimento de infraestrutura ${ }^{1}$ em um cenário marcado por conflitos ambientais. Neste caso, o objeto empírico é o mineroduto da Ferrous, que está em processo de licenciamento na microrregião de Viçosa, localizada na Zona da Mata de Minas Gerais.

Tendo em vista a grande quantidade de projeção de construções de empreendimentos de infraestrutura no Brasil, tida, para o estado, como necessária para o desenvolvimento do país, os conflitos ambientais constituem uma realidade que tende a ocupar cada vez mais espaço na sociedade para que se discuta sobre os problemas ocasionados. Pois, junto com a construção de grandes empreendimentos, como os de geração de energia e de mineração, transformações econômicas, sociais e ambientais ocorrem no território.

Dessa forma, os empreendimentos apresentam, para determinadas comunidades, impactos ambientais e mudanças em suas vidas, aspectos que podem e devem ser observados desde a elaboração do projeto até a fase de operação das obras.

Em suma, os conflitos ambientais são desencadeados por meio do processo de confrontação entre interesses divergentes dos atores sociais no que tange ao uso, apropriação e significação dos recursos de um território, principalmente, quando um dos atores projeta a implantação de um empreendimento com impactos que afetarão os demais membros direta ou indiretamente.

Assim, o caso do mineroduto da Ferrous é um exemplo de conflito ambiental ocasionado por um empreendimento. Se, por um lado, a construção dos empreendimentos de infraestrutura traz projeção ao crescimento do país e, consequentemente, ao seu desenvolvimento econômico, por outro lado, traz o empobrecimento das populações atingidas por estas obras, seja pela indenização paga pela terra, considerada, na maioria dos casos, abaixo do valor de mercado, pela

\footnotetext{
1 Empreendimento de infraestrutura refere-se às grandes obras como: usinas hidrelétricas, minerodutos, gasodutos, linhas de transmissão de energia, estradas, aeroportos, entre outras.
} 
perda das lavouras agrícolas utilizadas para o sustento de suas famílias ou de espaços simbólicos e culturais das comunidades atingidas.

Logo, ao estudar um caso que envolve conflito ambiental ocasionado por empreendimento de infraestrutura, deve-se considerar as condicionantes que moldaram o conflito, os interesses envolvidos e os atores sociais com os seus respectivos posicionamentos, além dos possíveis processos de cooperação dos grupos atingidos para amenizar os impactos negativos causados. Ou seja: compreender como a cooperação contribui para alcançar os objetivos de um determinado coletivo.

Sendo assim, uma das formas de organização dos indivíduos é a constituição de associação, caracterizada pela maneira que o grupo organizado formalmente realiza interesses comuns, na qual a ação coletiva permite melhores resultados do que as que os indivíduos teriam isoladamente.

\section{PROCEDIMENTOS METODOLÓGICOS}

A estratégia de construção metodológica adotada nesta pesquisa foi o estudo de caso, baseado nas observações de Ventura (2007), por ser exemplar, significativo, completo, considerar perspectivas e alternativas, apresentar evidências suficientes e ser elaborado de uma maneira atraente e única, por ser um caso específico e exclusivo.

Para alcançar o objetivo proposto para este trabalho, foi necessário escolher um empreendimento para se observar ações de resistência e de cooperação contra o mesmo. Para isso, foi escolhido o mineroduto da Ferrous, que, durante a pesquisa, encontrava-se em fase de licenciamento, com forte mobilização contrária à sua construção na microrregião de Viçosa.

O mineroduto escolhido terá uma faixa de servidão de 100 metros de largura e 400 quilômetros de comprimento. Ligará o complexo da Mina da Viga, em Congonhas - MG, ao porto da "Ferrous Ressources", em Presidente Kennedy - ES. Passará por 22 municípios, sendo 17 em Minas Gerais, três no Rio de Janeiro e dois no Espírito Santo, como pode ser visto na Figura 1. 
Figura 1. Localização do Mineroduto Ferrous desde o complexo da Mina da Viga, em Congonhas - MG, até ao porto da "Ferrous Ressources", em Presidente Kennedy - ES

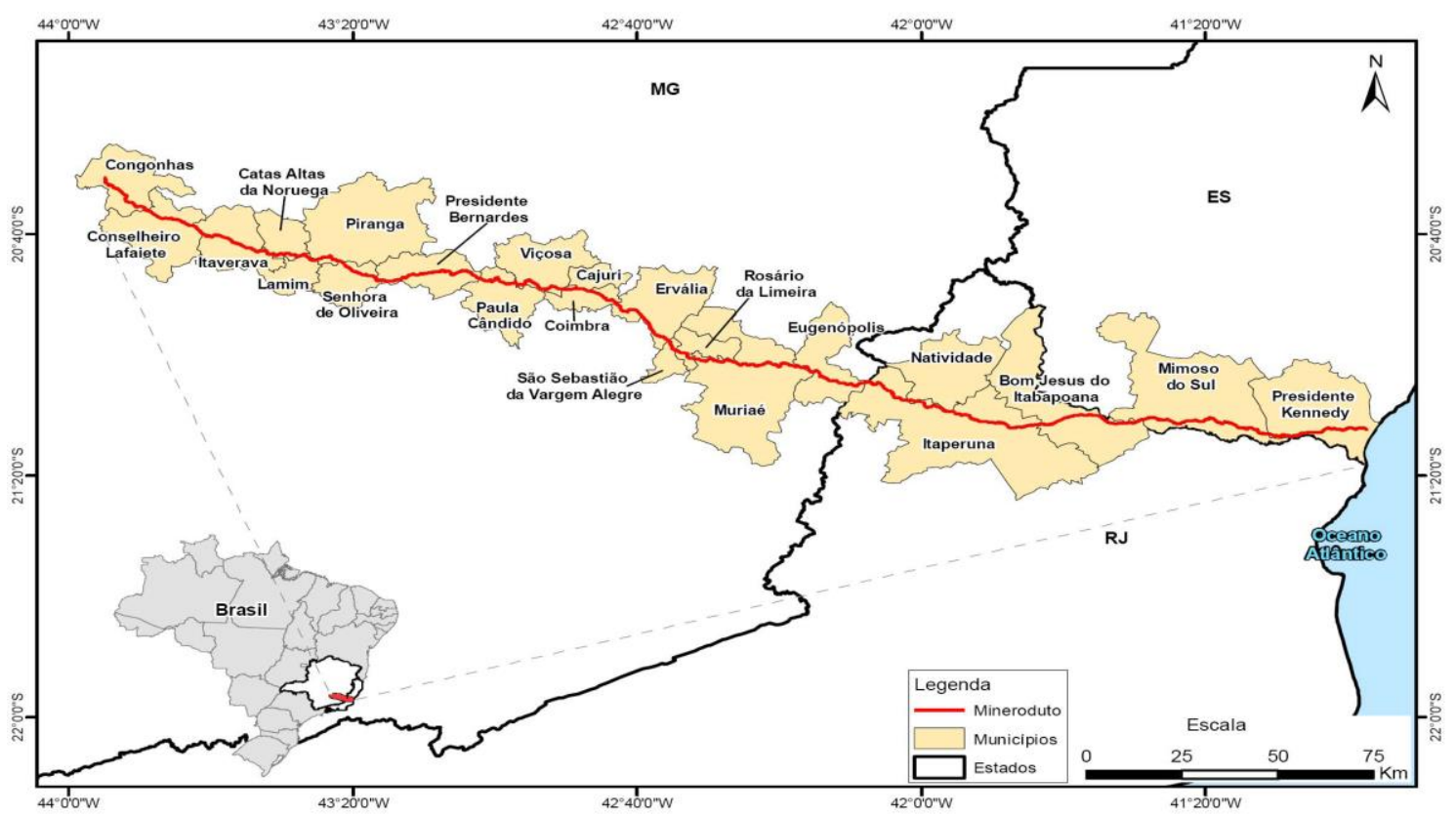

Fonte: Rima Ferrous - Minas Gerais, Rio de Janeiro e Espírito Santo (2010).

Em seguida, foi feita a escolha de uma região do trajeto do mineroduto para realizar a pesquisa, neste caso, a microrregião de Viçosa, localizada na Zona da Mata de Minas Gerais. Essa região, conforme apontam Zhouri e Rothman (2008), vem sendo um local com grandes potencialidades de construções de Usinas Hidrelétricas de Energia - UHEs e de Pequenas Centrais Hidrelétricas - PCHs. Isso se justifica em razão da Zona da Mata ter, no seu território, as bacias do Rio Doce e do Rio Paraíba do Sul, apresentando, assim, intensa atividade hídrica. Esses autores ainda revelam que, na década de 1990, foram construídos 15 empreendimentos de infraestrutura, denominados de "barragens", sendo que seis estão localizados na bacia do Rio Doce. Ainda segundo os estudiosos, empresas privadas e estatais, desde a década de 1960, vinham realizando estudos para a implantação desses empreendimentos na região.

Ademais, foi possível verificar que o Estado publicou a Avaliação Ambiental e Estratégica do Programa de Geração Hidrelétrica em Minas Gerais (PGHMG 2007-2027), o qual revelou que está previsto em Minas 
Gerais, implicando diretamente na Zona da Mata, a construção de 45 UHEs e 335 PCHs até o ano de 2027. A justificativa do governo para a construção dessas "barragens" está atrelada à projeção do aumento de consumo de energia elétrica nos próximos anos e ao desenvolvimento que se alavancará nas regiões nas quais os empreendimentos serão implantados.

Entretanto, Fonseca, Oliveira e Sousa (2012, p.296) chegaram à conclusão de que a implantação dos empreendimentos de infraestrutura, como as barragens e o mineroduto da Ferrous, na Zona da Mata "seguem o contexto de desenvolvimento econômico insustentável e da exploração dos recursos naturais e da população atingida, como já apontada em outros estudos". Ou seja, a construção de barragens e, possivelmente, do mineroduto não trará desenvolvimento para essa região.

Além disso, a escolha da microrregião de Viçosa para este estudo se deu em razão do local também abarcar as maiores manifestações contrárias a implantação do mineroduto da Ferrous, o que culminou na criação de uma campanha denominada "Campanha pelas Águas e Contra - Mineroduto da Ferrous". Essa campanha foi criada a partir da organização de vários atores sociais atingidos e não atingidos (movimentos sociais e estudantis), e tem por objetivo criar espaços para discutir e informar os atingidos e a comunidade em geral sobre os impactos que poderão ser causados pelo mineroduto e, ainda, criar mecanismos de resistência contra tal empreendimento.

Assim, esse processo de cooperação foi desencadeado pela ocorrência do conflito ambiental ocasionado pelo mineroduto da Ferrous nessa microrregião. Só para esclarecimento, o mineroduto atingirá, aproximadamente, 308 propriedades rurais, inseridas no recorte espacial deste estudo, sendo: 92 em Viçosa, 71 em Coimbra, 90 em Ervália, 53 em Paula Cândido e 02 em Cajuri (RELATO DO REPRESENTANTE DA FERROUS, 2012).

Tendo definido o empreendimento e a região da pesquisa, foram feitas revisões bibliográficas sobre as temáticas "conflito ambiental" e "associativismo" para subsidiar esta análise.

A coleta de dados, por sua vez, foi realizada por meio do trabalho de campo, com o uso da técnica da entrevista semiestruturada. As 
entrevistas foram aplicadas a 9 atores sociais (ver Quadro 01), escolhidos a partir de uma amostra não probabilística, selecionados pelo critério de intencionalidade com base nos seguintes critérios: ser atingido pelo empreendimento, ser participante das reuniões promovidas pelos mediadores, fazer parte do movimento social envolvido no conflito e ter envolvimento no surgimento e/ou no desdobramento do conflito ambiental ocasionado pelo mineroduto.

Quadro 1. Atores sociais entrevistados, Viçosa, 2012

\begin{tabular}{|l|}
\hline ATORES SOCIAIS ENTREVISTADOS \\
\hline Um atingido pelo mineroduto representando a comunidade rural de Viçosa. \\
\hline Um atingido pelo mineroduto representando a comunidade rural de Coimbra. \\
\hline Um representante da empresa Ferrous Ressources. \\
\hline Um representante da promotoria da Comarca de Viçosa. \\
\hline Um representante do Movimento dos Atingidos por Barragens da Zona da Mata \\
Mineira. \\
\hline Um representante da Entidade Nacional de Estudantes de Biologia. \\
\hline Um representante do Levante Popular da Juventude. \\
\hline Um representante da Associação dos Moradores do Bairro Santa Clara. \\
\hline Um representante do Blog Viçosa Cidade Aberta. \\
\hline
\end{tabular}

Fonte: Dados da pesquisa, 2012.

É importante destacar que, para se chegar a essa amostra, foram coletadas informações junto às entidades que compõe a "Campanha pelas Águas e Contra o Mineroduto da Ferrous". De posse do número de entrevistados, construiu-se o roteiro de entrevista que serviu de suporte para o levantamento das informações.

As entrevistas foram aplicadas no segundo semestre de 2012, no Município de Viçosa, e teve uma duração média de 40 minutos cada.

Outra fonte de dados deste trabalho foi a pesquisa documental. Os documentos utilizados na pesquisa foram: Estudo de Impactos Ambientais do Mineroduto Ferrous-EIA2, Relatório de Impactos Ambientais do Mineroduto da Ferrous-RIMA2, Relatório sobre os

\footnotetext{
2 Esses são documentos técnicos que apresentam dados específicos das características dos municípios pertencentes ao trajeto da passagem do mineroduto como - o diagnóstico do meio socioeconômico, do meio biótico e do meio físico, e, por fim, a avaliação dos impactos - e ainda analisa as consequências da implantação do empreendimento no meio ambiente.
} 
impactos socioambientais do mineroduto da Ferrous Ressources na microrregião de Viçosa e, por fim, o ofício da ouvidoria ambiental do Estado de Minas Gerais sobre o mineroduto da Ferrous.

Além desses documentos, foram selecionadas matérias publicadas nos jornais impressos e nas publicações eletrônicas sobre o mineroduto da Ferrous na microrregião de Viçosa, no período de janeiro de 2010 a fevereiro de 2013. Posteriormente, foi construído um banco de dados com as notícias, no qual foram agrupadas e analisadas. Essa análise permitiu confirmar as causas e os desdobramentos dos conflitos ambientais, os atores sociais envolvidos neste estudo de caso e identificar as ações de resistência contra a implantação do empreendimento em estudo.

Ademais, foi possível acompanhar as reuniões das comunidades atingidas e da Campanha; audiências públicas em Viçosa e Paula Cândido; Audiência Pública da Comissão de Minas Energia da Assembleia Legislativa de Minas Gerais; Caminhada na Feira Livre do Produtor Rural de Viçosa; Marcha contra o mineroduto da Ferrous e em defesa das águas; e Audiência Pública promovida pelo Ministério Público do Estado de Minas Gerais-MPMG.

\section{CONFLITOS AMBIENTAIS: CAUSAS, DESDOBRAMENTOS E ATORES SOCIAIS}

O surgimento do conflito ambiental na microrregião de Viçosa se deu a partir da iminência de implantação do mineroduto da Ferrous, pois a realização do empreendimento sem a devida discussão e consentimento dos atores sociais envolvidos, sobretudo dos atingidos, provocou tal embate. A partir daí, o conflito foi se desdobrando por meio dos seguintes temas:

a) Valor das indenizações da terra:

Em 2009, os representantes da Ferrous iniciaram as visitas às comunidades atingidas com o objetivo de coletar informações sobre as propriedades rurais que estavam no trajeto de passagem do mineroduto para elaboração do EIA/RIMA. Porém, a informação de que seria implantado o mineroduto foi divulgada em 2010 por meio das reuniões 
promovidas pelo empreendedor com as comunidades atingidas. Segundo um dos atingidos (2012),

\begin{abstract}
nessas reuniões eles abordavam o tema da indenização, mas sempre de maneira muito confusa, porque, eles não deixavam bem claro como seriam as regras pra indenização. Em algum momento eles falaram que o pagamento era feito integral, outra vezes eles falaram que era feito um adiantamento de cinquenta por centro e depois reembolsado o restante. Nunca falaram em prazo de indenização. Oh vocês vão ser indenizados assim que fincar uma placa nas suas propriedades, ou vocês vão ser indenizados assim que a gente fizermos a negociação, ou seja, eles nunca falaram em prazo de tempo. Então isso sempre foi uma inquietação entre os produtores proprietários e eu participei de várias reuniões não só na minha região mais em outras também, fiz questão de ir e eu pude perceber que o grande questionamento dos proprietários era esse, como é que vai ficar a questão de indenização? Por que eles nunca falavam em uma coisa concreta que pudesse dar segurança pro atingido (RELATO DO REPRESENTANTE DA COMUNIDADE RURAL DE COIMBRA, 2012).
\end{abstract}

Após alguns meses, os atingidos foram notificados e a primeira parcela do dinheiro das indenizações foi depositada em juízo. De acordo com um atingido, não houve "negociação" das terras, o que aconteceu foi que a partir de "uma foto aérea que eles fizeram antes do trabalho de mapeamento, eles, sem visitarem a propriedade, já estipularam um valor de indenização" (RELATO DO REPRESENTANTE DA COMUNIDADE RURAL DE VIÇOSA, 2012).

Além disso, vários atingidos relataram, nos meios midiáticos e nas audiências públicas, que os valores estavam sendo calculados com base no tamanho dos imóveis, sem levar em consideração sua localização, benfeitorias, valores culturais e produção agrícola. Em razão dessas particularidades não terem sido consideradas pelo empreendedor, os mesmos entraram com ações judiciais referente às indenizações.

É importante esclarecer que, na vivência de campo, foi possível perceber, também, que existem alguns atingidos, a minoria, posicionando-se a favor do empreendimento, alegando que as indenizações pagas pela Ferrous estão justas e corretas. 
Para melhor entender tal impasse, um dos entrevistados alega que "ela (empresa Ferrous) escolhe o público que ela vai tratar melhor entre aspas (RELATO DO REPRESENTANTE DA ENEBIO, 2012)". Como também é exposto por outro entrevistado:

\begin{abstract}
comigo que eu era professora eles conversaram com um tom e ofereceram outro valor, com meu vizinho que era agricultor, que era analfabeto, eles ofereceram outro valor e negociaram com outro tom. Não é só porque o cara é analfabeto que ele não tem o mesmo direito que ela. Porque ele é analfabeto, a terra dele vai valer menos no mercado? (RELATO DO REPRESENTANTE DO LEVANTE POPULAR DA JUVENTUDE, 2012).
\end{abstract}

Diante disso, é possível analisar que o valor das indenizações não foi estabelecido a partir de critérios rigorosos e padronizados, pois a Ferrous não divulgou como foi calculado. Caso contrário, o empreendedor teria como informar e explicar para os atingidos a forma de avaliação do valor da indenização. Ademais, pode-se observar nas falas dos entrevistados que houve critérios diferenciados para a negociação das terras.

b) Falta de informações sobre a implantação do mineroduto:

Esse argumento se iniciou quando a Ferrous realizou as reuniões com as comunidades atingidas. Posteriormente, o assunto ganhou seguimento na audiência pública promovida pelo empreendedor, no início do ano de 2011, no Município de Viçosa, atendendo aos municípios atingidos inseridos na microrregião estudada.

A audiência pública faz parte do processo de licenciamento ambiental do empreendimento e teve como objetivo apresentar o projeto e os resultados do EIA para os cidadãos interessados, como forma de sanarem suas dúvidas e apresentarem críticas e sugestões ao projeto. Porém, na perspectiva das pessoas que estavam na audiência, não houve uma discussão clara e aprofundada sobre a construção do mineroduto e nem foi dada a oportunidade para a maioria dos participantes fazerem perguntas.

$\mathrm{Na}$ verdade, essa audiência causou frustrações aos ouvintes, uma vez que tiveram poucas oportunidades de questionar sobre a obra, pois o empreendedor não apresentou quais seriam realmente os impactos 
sociais e ambientais ocasionados pela implantação do mineroduto, além de não ter abordado o assunto da indenização. Isso fez com que os atingidos ficassem indignados com a situação.

De acordo com Bronz (2011, p.38), "as audiências públicas são os principais 'ritos' cerimoniais dos procedimentos de licenciamento ambiental". Isto é, nas audiências, os consultores do EIA do empreendimento apresentam várias informações sobre as comunidades atingidas com o intuito de gastar tempo para não apresentar as informações tidas como importantes para os atingidos (impactos, indenizações, área atingida, entre outros), assim como, para não responder as suas perguntas.

Nessa perspectiva, de acordo com o relato supracitado, pode-se dizer que a Ferrous também utilizou desse mecanismo para não informar os atingidos sobre os assuntos que os interessavam.

Outro episódio que marca esse argumento contra a implantação do mineroduto pode ser observado por meio do seguinte relato:

a um tempo atrás, passou um pessoal na minha região lá onde eu tenho um sítio, fincando uma estacas na estrada, então ao longo da estrada de terra foram fincadas algumas estacas e aí eu procurei saber com meus vizinhos e com rapaz que trabalha pra mim. Eles falaram que ficaram sabendo que era de um mineroduto que ia passar e aí o pessoal simplesmente fincou a placa do mineroduto na estrada. Então no primeiro momento, até o pessoal achou que ia passar na estrada, ao longo da estrada, aproveitando o leito da estrada. E eles não falaram nada com vocês? Nada, os produtores em nenhum momento foram procurados para serem informados do que se tratava, até porque como eles estavam fincando placa na estrada. Então, a princípio eles não precisavam dar muita satisfação porque estava em via pública então ficou um negócio já desde o início meio sem comunicação (RELATO DO REPRESENTANTE DA COMUNIDADE RURAL DE COIMBRA, 2012).

Após alguns meses, diversos proprietários rurais dos municípios de Viçosa e Coimbra começaram a deparar com placas em suas propriedades com os dizeres "FAIXA DE SERVIDÃO - Construção do Mineroduto da Ferrous", o que foi entendido, pela maioria, como invasão em suas propriedades. Segundo eles, ninguém da Ferrous 
comunicou a respeito da instalação das placas nas suas terras. Esse episódio foi registrado por meio de boletim de ocorrência, por todos os proprietários que se sentiram incomodados por não terem recebido nenhuma informação do empreendedor (DEPOIMENTOS DOS ATINGIDOS PELO MINERODUTO DA FERROUS NA AUDIÊNCIA POPULAR, CÂMARA DOS VEREADORES DE VIÇOSA, 2012).

Outro episódio que merece destaque ocorreu quando a Ferrous contratou agentes sociais para fazer o trabalho de diálogo face a face com os atingidos. Os agentes teriam uma rotina de visita nas casas das pessoas atingidas para levantar questionamentos, sanar dúvidas e esclarecer sobre o tipo de assistência técnica e extensão rural, por exemplo. A partir dessa ação, o empreendedor pressupunha um estreitamento do relacionamento entre a Ferrous e os atingidos (RELATO DO REPRESENTANTE DA FERROUS, 2012), todavia, na prática, isso não aconteceu.

O relacionamento funcionou da seguinte maneira: o agente social $X$ vai à propriedade de um atingido para iniciar o diálogo. $O$ proprietário faz questionamentos sobre o mineroduto, mas a maioria das perguntas não são respondidas pelo agente, o qual se prontifica a respondê-las na próxima visita. Nesta próxima, porém, aparece o agente social $Y$ e 0 atingido relata para ele que o agente $X$ ficou responsável de trazer as respostas dos questionamentos realizados na última visita. $O$ agente $Y$ argumenta que não recebeu nada sobre tais perguntas e que também não sabe das respostas. Assim, os atingidos não conseguem obter informações sobre suas dúvidas em relação ao empreendimento por meio dos agentes (RELATO DO ATINGIDO PELO MINERODUTO DA FERROUS NA AUDIÊNCIA PÚBLICA PROMOVIDA PELO MPMG, 2012).

Diante desse panorama, pode-se inferir que o empreendedor não apresenta ter uma comunicação aberta, clara e contínua com os proprietários atingidos. Sendo assim, subentende-se que existe falta de informações ou recusa em fornecê-las por parte dos representantes da Ferrous.

c) Prejuízos econômicos e ambientais nas propriedades atingidas

A maioria das propriedades rurais que estão no trajeto da passagem do mineroduto tem algum tipo de produção agrícola. Para 
implantar o mineroduto foi necessário demarcar uma faixa de servidão de 100 metros que traz diversas restrições às propriedades, como: fazer queimadas; trafegar com veículos pesados; fazer escavações, usar arado e outros implementos agrícolas em profundidades do solo superior a 60 centímetros; implantar culturas de médio e grande porte; e fazer quaisquer construções. Além disso, como consequência, a faixa de servidão ocasionará perda da privacidade no uso da propriedade; dificuldade de acesso a trechos isolados pela faixa; restrições no aproveitamento econômico; dificuldade na recomposição do solo; e, por último, o desequilíbrio ecológico dessa região.

Sendo assim, os proprietários que sobrevivem da renda da produção e comercialização de produções agrícolas alegam que estão sendo injustiçados. Com o mineroduto, as propriedades correm o risco de não servirem mais para a produção agrícola.

Ademais, como as propriedades rurais são cercadas por fragmentos de matas e por várias nascentes, os atingidos acreditam que terão prejuízos ambientais, pois, em alguns locais, provavelmente, o mineroduto irá passar por cima destes ambientes, causando o desabastecimento de algumas propriedades e a modificação da paisagem natural, prejudicando o seu valor comercial.

Portanto, os atingidos alegam que terão prejuízos econômicos e ambientais em suas propriedades com a passagem de tal empreendimento, e que o valor da indenização não cobre tais prejuízos. Além disso, os atingidos não estão de acordo com a desapropriação de determinados locais em suas propriedades.

d) Problema da falta de água no município de Viçosa futuramente

O Município de Viçosa é abastecido pela água do ribeirão São Bartolomeu e do rio Turvo, sendo que o primeiro abastece $50 \%$ do Município de Viçosa e $100 \%$ da Universidade Federal de Viçosa-UFV, e o segundo abastece o restante do município. No início do ano de 2012, os bairros mais altos de Viçosa, como Santa Clara, Lourdes, Nova Viçosa, Fátima, Bom Jesus, São Sebastião, Estrelas, dentre outros que são abastecidos com a água do São Bartolomeu, tiveram problemas de falta de água em plena época chuvosa. Os moradores receberam abastecimento de água por caminhões pipas durante três semanas. 
O fato mobilizou os moradores, que procuraram o SAAE para esclarecimentos. A autarquia deixou claro que está fazendo o possível e que todas as medidas cabíveis estão sendo devidamente providenciadas. O ex-professor da UFV e especialista em hidrologia e manejo de pequenas bacias hidrográficas, Osvaldo Ferreira Valente, esclareceu para os leitores que a atual falta de água nos bairros mais altos de Viçosa é resultado da diminuição da vazão de água do Ribeirão São Bartolomeu, situado nas bandas do Paraíso, Palmital e Córrego do Engenho. E deixou claro que, se quisermos solucionar o problema, é preciso trabalhar pela revitalização e conservação do São Bartolomeu, para que este aumente sua vazão (JORNAL FOLHA DA MATA, 2012, p.10).

A partir dessa divulgação, a relação do problema da falta de água em Viçosa com a possível passagem do mineroduto nas áreas das nascentes do ribeirão São Bartolomeu foi sendo analisada por discentes e docentes da UFV.

Dessa forma, observou-se, por meio do EIA do empreendimento, que o mineroduto irá passar em 30 nascentes do município, sendo que seis estão localizadas na bacia do ribeirão São Bartolomeu.

Contudo, o relatório da Associação dos Geógrafos Brasileiros (2012) identificou que há, no mínimo, 60 nascentes no trajeto de Viçosa, sendo que 30 estão na bacia do ribeirão São Bartolomeu, sobretudo, na região do Paraíso, Palmital e Córrego do Engenho. Dessa forma, pode-se inferir que o número de nascentes afetadas pelo mineroduto da Ferrous é superior ao apresentado no EIA produzido pela empresa.

Em razão da repercussão do caso, a empresa Ferrous se pronunciou ao jornal Tribuna Livre, sendo publicada a matéria no dia 24 de maio de 2012, informando e garantindo aos leitores que o mineroduto não atingirá nascentes do ribeirão São Bartolomeu.

Os representantes da mineradora disseram textualmente que, "com o objetivo de garantir a preservação das nascentes, a Ferrous cadastrou e monitorou a vazão tanto das nascentes quanto dos cursos d'águas em tida a extensão do mineroduto". Disseram ainda que "o abastecimento de água dentro de Viçosa não será 
prejudicado, pois não haverá impacto em nenhum dos mananciais que abastece a cidade". Foi mencionado ainda que durante as obras o mineroduto poderá afetar temporariamente o abastecimento em pontos isolados, podendo impactar algumas propriedades localizados na zona rural (JORNAL TRIBUNA LIVRE, 2012, p.5).

Após essa informação, a empresa não se proferiu em público. Portanto, ao analisar a situação do ribeirão, percebe-se que, se o mineroduto passar em cima das nascentes do mesmo, o Município de Viçosa terá sérios problemas com o abastecimento de água, uma vez que tal problema já existe.

As possíveis e principais consequências de um desabastecimento futuro será a paralização das aulas da UFV e das faculdades particulares da cidade, o êxodo da população viçosense para outros municípios e a crise na economia local.

Por fim, os principais atores sociais contrários à implantação do mineroduto, em razão do problema da água, são: atingidos pelo mineroduto, Câmara dos Vereadores de Viçosa ${ }^{3}$, Ministério Público de Viçosa, Movimento dos Atingidos por Barragens-MAB, Projeto de Assessoria as Comunidades Atingidas por Barragens na Zona da Mata Mineira-PACAB4, Entidade Nacional de Estudantes de Biologia-ENEBio, Núcleo de Assessoria às Comunidades Atingidas por Barragens-NACAB, Movimento dos Trabalhadores Sem Terra-MST, Levante Popular da Juventude, Associação dos Moradores do Bairro Santa Clara, Associação dos Moradores do Bairro Palmital, Associação dos Geógrafos BrasileirosAGB, Paróquia Nossa Senhora de Fátima de Viçosa e estudantes da UFV.

Já os argumentos a favor da implantação do mineroduto são:

a) O discurso das vantagens do mineroduto segundo o empreendedor:

A empresa mineradora Ferrous Ressources do Brasil S/A argumenta, em seus discursos, que o mineroduto é mais seguro quando

3 É importante explanar que apesar da Câmara ter sido contrária à implantação do mineroduto, há vereadores que não se posicionaram. Além disso, a análise da Câmara foi feita com a gestão que se encerrou em 2012.

4 O PACAB é um projeto de extensão coordenado por professores do Departamento de Economia Rural da Universidade Federal de Viçosa. 
comparado com outros meios de transporte. É menos impactante ambientalmente, pois evita o tráfego de caminhões pesados (cerca de 800 por dia) próximo às comunidades e às rodovias, preservando, dessa forma, a qualidade do ar, além de reduzir riscos de acidentes ambientais e humanos. Justifica, ainda, que o mineroduto é necessário porque a Ferrous possui um grande projeto de mineração de ferro em Minas Gerais, e precisa levar todo o minério até seu porto, no Espírito Santo, para escoar a produção para o exterior, podendo, assim, movimentar a economia brasileira (RIMA FERROUS, 2010).

Além disso, durante a fase de obras, o empreendimento traz a oferta média de mil empregos, sendo que estes postos de trabalhos exigem uma formação qualificada e, ainda, proporciona a geração de impostos nos municípios. Dessa forma, isso "pode alavancar também o desenvolvimento local" na perspectiva do representante do empreendedor (RELATO DO REPRESENTANTE DA FERROUS, 2012).

Enfim, no discurso da empresa não aparece que o mineroduto trará impactos negativos, o que se observa é que os proprietários terão apenas alguns incômodos com barulho quando a construção estiver em curso.

No entanto, ao se analisar algumas matérias dos jornais impressos no Município de Viçosa, áudios da Assembleia Popular na Câmara de Viçosa e da Assembleia Popular promovida pelo MPMG, assim como relatórios técnicos sobre o empreendimento, observa-se que o mineroduto traz e trará impactos para a população em geral, como, por exemplo: o desabastecimento de água no Município de Viçosa e nas propriedades rurais, supressão de áreas produtivas, dentre outras.

b) Recebimento de um Decreto de Utilidade Pública do Mineroduto da Ferrous:

Todas as áreas necessárias para as obras e a passagem do Mineroduto da Ferrous receberam o decreto de utilidade pública por intermédio do governador do Estado de Minas Gerais. Esse documento informa que: 
declara de utilidade pública, para desapropriação, constituição de servidão administrativa e ocupação temporária, terrenos situados nos Municípios que menciona, necessários à construção do Mineroduto Ferrous, bem como de suas instalações complementares, e dá outras providências (DECRETO S/N. DE UTILIDADE PÚBLICA, 2009).

Isto é, esse decreto autoriza as desapropriações das terras para as obras da empresa Ferrous Ressources. O decreto foi publicado e validado em maio de 2009. Contudo, a primeira licença, a Licença Prévia, que o empreendedor deveria ter recebido do Instituto Brasileiro do Meio Ambiente e dos Recursos Naturais Renováveis-IBAMA para iniciar o planejamento da construção do mineroduto só foi concedida em 22 de junho de 2011.

Desse modo, percebe-se que houve uma antecipação do órgão executivo frente ao órgão ambiental, fazendo com que o projeto da Ferrous fosse executado de maneira mais "confortável" para o empreendedor. O órgão executivo já adianta os trâmites jurídicoburocráticos indispensáveis para o processo de desapropriação das terras para a implantação do mineroduto, antes mesmo da Ferrous ter a Licença Prévia em mãos. Além do apoio do governador de Minas Gerais, o empreendedor tem o apoio do atual prefeito do Município de Viçosa.

Ao analisar o recebimento desse decreto, percebe-se que o empreendedor possui uma valiosa ferramenta de persuasão para convencer as pessoas atingidas, uma vez que a autoridade do Estado de Minas Gerais, que é responsável por gerir os interesses da população mineira, deu o seu aval positivo para a implantação de tal empreendimento.

\section{ESTRATÉGIAS DO EMPREENDEDOR PARA A IMPLANTAÇÃO DO MINERODUTO}

Para executar o projeto do mineroduto, a Ferrous utiliza de várias estratégias para que o empreendimento saia do papel. Primeiramente, buscou o apoio do governador de Minas Gerais, que retribuiu com a entrega de um de Decreto de Utilidade Pública do Mineroduto da Ferrous. 
Segundo, as audiências públicas promovidas pelo empreendedor, as quais fizeram parte do processo licenciamento, foram apresentadas com informações que as pessoas presentes na audiência já sabiam. Já as informações que o público gostaria de saber, como: impactos, indenizações, área atingida, benefícios do empreendimento, dentre outros, não foram apresentadas. Essa tática é utilizada pelos empreendedores para não ter muito tempo de responder as dúvidas das pessoas e para não falar sobre os pontos negativos do empreendimento. Dessa forma, o empreendedor transmite somente sua perspectiva a respeito da obra.

Terceiro, a Ferrous utiliza agentes sociais para demonstrar para a sociedade em geral que ela tem um relacionamento direto e contínuo com as comunidades atingidas, mas na prática isso não acontece.

Por fim, em dezembro de 2012, a Ferrous divulgou notas na imprensa e contactou os proprietários informando-os que a execução do projeto do mineroduto seria adiada para 2016. A justificativa desse adiamento seria em razão da baixa do valor do minério de ferro, fator que não justificaria o investimento na construção no ano supracitado, uma vez que a mina também não estaria produzindo a quantidade de minério planejada.

Além disso, o empreendedor deixa claro nos seus discursos que não desistiu do mineroduto e que, apesar do adiamento, a empresa trabalha arduamente no processo de licenciamento ambiental, isto é, do recebimento da Licença de Instalação.

Tendo em vista o grande número de ações de mobilização contra a implantação do empreendimento, no ano de 2012, na microrregião de Viçosa e posteriormente em outros municípios que também serão atingidos (Conselheiro Lafaiete e Muriaé), pode-se inferir que se trata de uma estratégia da empresa para que as pessoas envolvidas nas manifestações desanimem e se esqueçam da implantação do mineroduto. De tal modo que, com o passar dos anos, a população passe a não se lembrar dos pontos negativos do empreendimento. Então, em 2016, a Ferrous refaz o marketing positivo e apresenta para a população que o trajeto do mineroduto foi modificado para não passar nas nascentes. Assim, o problema ambiental da água estaria resolvido. 
Processo de cooperação como ferramenta de organização entre grupos atingidos por grandes...

Redes (St. Cruz Sul, Online), v. 20, n² 2, p. 336 - 359, maio/ago. 2015354 


\section{O PROCESSO DE COOPERAÇÃO COMO FERRAMENTA DE ORGANIZAÇÃO ENTRE OS GRUPOS ATINGIDOS PELO O MINERODUTO DA FERROUS}

O associativismo é uma forma de cooperação que vem se desenvolvendo entre os homens desde a antiguidade, quando a humanidade vivia nas comunidades naturais, com o propósito de solucionar problemas que não eram resolvidos individualmente. Além disso, o homem encontrava no coletivo a proteção e os meios materiais necessários à sobrevivência da vida.

Jesus e Tiriba (2003) argumentam que a noção de cooperação está ligada à ideia de ajuda mútua, de contribuir com o coletivo, tendo em vista a oposição à perspectiva individualista. Esse conceito também se assemelha ao encontrado no Dicionário de Ciências Sociais, publicado em 1987, que define o termo cooperação como uma forma de trabalho em conjunto, em contraste com a concorrência ou a oposição.

Contribuindo com essa discussão, Frantz (2001, p.1) pontua que a cooperação é

um processo social, embasado em relações associativas, na interação humana, pela qual um grupo de pessoas busca encontrar respostas e soluções para seus problemas comuns, realizar objetivos comuns, busca produzir resultados, através de empreendimentos coletivos com interesses comuns.

Assim, para que haja sucesso na obtenção dos objetivos comuns, são necessárias determinadas condições que a cooperação implica, como: a confiança recíproca entre os indivíduos, a existência de interesses comuns, o consenso em relação aos fins a atingir e a participação ativa de todos.

Nesse sentido, Ring e Van de Ven (1994) argumentam que as relações de cooperação, desencadeadas pelos indivíduos, constituem-se como mecanismos sociais para a ação coletiva e que são reestruturados por ações e interpretações dos atores envolvidos.

Tendo em vista a implantação do mineroduto e os impactos negativos vindos deste empreendimento, os proprietários das 
comunidades atingidas começaram a se reunir para discutir a respeito dos valores das indenizações, dos prejuízos econômicos e ambientais.

Diante de tantas reuniões, a comunidade rural Córrego dos Moinhos do Município de Coimbra avançou seus debates e iniciou a discussão sobre o que poderia ser feito para aumentar o valor das indenizações. Uma vez que, para eles não teriam como fazer nada para impedir a construção do empreendimento, já que o mineroduto tinha um decreto de utilidade pública.

Dessa forma, essa comunidade resolveu realizar uma reunião, em junho de 2011, no campo Milton Ladeira, em Coimbra, com dois vereadores da comarca de Viçosa e os atingidos dos municípios de Paula Cândido, Viçosa, Cajuri e Ervália para conseguirem juntar um número maior de pessoas para juntos resolverem o problema do valor da indenização e dos prejuízos econômicos e ambientais.

No final da reunião, os proprietários pediram apoio das autoridades presentes. Os vereadores viçosenses declararam e aceitaram o pedido e aproveitaram para afirmar sobre a importância desse grupo se reunir com os demais que estão passando pelos mesmos problemas. Nessa reunião, ainda, os vereadores sugeriram que fosse constituída uma "associação para reivindicar e cobrar por seus direitos junto às autoridades competentes" (JORNAL FOLHA DA MATA, 2011, p.11).

A associação é uma forma de organização formal dos indivíduos, de forma democrática, que tem a finalidade de defender interesses comuns, podendo estes ser derivados de questões econômicas, científicas, culturais, espirituais, ideológica, e motivos sociais. A associação visa superar dificuldades e gerar benefícios para os indivíduos associados.

Para Wautier (2001, p.11), "a principal função das associações é uma função social: constituídas de membros solidários, elas visam a constituição de uma comunidade de interesses baseada na defesa dos direitos sociais". Além disso, a autora afirma que as associações constituem maneiras de inserção social e de responsabilidade dos indivíduos, adquirindo, assim, o papel de mediação entre cidadãos e instituições e, também, cidadãos e Estado. 
Defourny (1992) apresenta um modelo de tipologia das associações, quais sejam: a primeira, associações de expressão e de comunicação (os clubes, entre outros); a segunda, associações de gestão (esporte, cultura, lazer, entre outros); e a terceira, associações de reivindicação (militantes e de pressão). Essa proposta de tipologia teve como critério o modo de ação coletiva. A classificação demonstra que não há só associações de cunho de gestão e de expressão, como a maioria dos estudiosos deste assunto apresenta, mas há, também, associações de grupos de reivindicação.

De um modo geral, o que se deve perceber como característica que diferenciou as associações ao longo de sua história, é que:

algumas manifestam o interesse dos indivíduos, de juntos, se sentirem bem, são uma espécie de refúgio em que se pode, de uma forma ou outra, dar um certo grau de satisfação pessoal. Outras, ao contrário, desenvolvem atividades que se inscrevem na lógica da ação coletiva militante e da historicidade. Isto é: sua finalidade é a ação sociopolítica que busca a construção de um mundo que thes parece melhor, mediante a mobilização dos participantes, baseada num ideal de justiça e solidariedade (WAUTIER, 2001, p.31).

Em termos práticos, as associações atuais são importantes para a sociedade civil, pois elas operam para captar recursos, acessar políticas públicas, defender os direitos das pessoas e o estabelecimento de condições que desafiam a humanidade, como podem ser as questões referentes ao meio ambiente e ao desenvolvimento sustentável.

Nesse sentido, de acordo com o art. 53 do Novo Código Civil Brasileiro, publicado em 2002, as associações são constituídas por pessoas que se organizam para fins não econômicos. Isso significa que a associação é criada com o propósito de prestar serviços a determinado grupo de pessoas sem destinar lucros financeiros.

Valadares (2009) argumenta que o associativismo é toda iniciativa formal ou informal por meio de um grupo de pessoas que busca alcançar interesses comuns. Após consolidada a organização desse grupo, o cumprimento das formalidades legais apresenta forma jurídica ao grupo associativo, como a Associação. O mesmo autor ainda enfatiza que esse tipo de empreendimento coletivo é caracterizado por: 
a) reunir duas ou mais pessoas físicas ou jurídicas para a realização de objetivos comuns;

b) ter seu patrimônio constituído pela contribuição dos associados, doações, subvenções, etc.;

c) seus fins podem ser alterados pelos associados, em Assembleia Geral;

d) os seus associados deliberarem livremente em Assembleia Geral tendo, cada associado, direito a um voto;

e) serem entidades de direito privado e não público (VALADARES, 2009, p.2).

Dessa maneira, as Associações são dirigidas por uma diretoria eleita, as quais estão subordinadas à vontade coletiva e democrática de seus associados, e por normas descritas no seu Estatuto Social, aprovado em Assembleia Geral (VALADARES, 2009).

Outra comunidade atingida que também vem se reunindo é a comunidade rural do Palmital, localizada em Viçosa. Esse grupo debate o mesmo ponto que a comunidade de Coimbra, em razão dos impactos já pontuados no decorrer deste trabalho, do surgimento do problema de água e da relação da falta de água com a passagem do mineroduto nas nascentes do ribeirão São Bartolomeu, uma vez que esta comunidade tem muitas nascentes que desembocam neste ribeirão. A comunidade do Palmital constituiu a Associação dos Moradores do Bairro Palmital para ter mais recursos para resolver os seus problemas. De acordo com o seu presidente, a associação representa que "juntos somos mais fortes" (RELATO DO REPRESENTANTE DA COMUNIDADE RURAL DE VIÇOSA, 2012). Ao falar de recursos, neste caso, remete à organização formal que possui um Cadastro Nacional de Pessoa Jurídica-CNPJ, pois, por meio desta formalização é possível entrar com uma ação civil coletiva em defesa do ribeirão São Bartolomeu.

É importante explanar que, para entrar com uma ação civil coletiva, é necessário que se tenha uma associação que represente o interesse do coletivo, estipulado no seu estatuto, e que a mesma esteja funcionando há mais de um ano (AUGUSTO, 2009). O presidente da Associação do Palmital está esperando que a organização complete um ano para entrar com a ação civil.

Diante das questões relacionadas ao valor da indenização da terra, falta de informações sobre a implantação de tal empreendimento e dos 
possíveis prejuízos econômicos, os representantes das entidades ENEBio, PACAB, MAB, MST, Levante Popular da Juventude, Associação dos Moradores do Bairro Palmital, Paróquia Nossa Senhora de Fátima de Viçosa, estudantes da UFV e os atingidos dos municípios de Coimbra e Viçosa iniciaram o processo de construção da "Campanha pela Águas e Contra o Mineroduto da Ferrous" a partir das ações de mobilização na microrregião de Viçosa. No Quadro 2 é possível ver as principais manifestações que aconteceram antes de construir a campanha.

Quadro 2. Principais manifestações mapeadas contra o mineroduto da Ferrous, 2011-2012

\begin{tabular}{|c|c|}
\hline $\begin{array}{c}\text { Tipos de } \\
\text { manifestações }\end{array}$ & Descrições das manifestações \\
\hline $\begin{array}{l}\text { Audiência Pública da } \\
\text { Comissão de Minas } \\
\text { Energia da Assembleia } \\
\text { Legislativa de Minas } \\
\text { Gerais, realizada em } \\
\text { dezembro de } 2011 \text {, } \\
\text { no Município de } \\
\text { Viçosa. }\end{array}$ & $\begin{array}{l}\text { Essa audiência teve o objetivo de realizar o debate sobre os } \\
\text { impactos da construção do mineroduto da Ferrous entre } \\
\text { Congonhas (MG) e Presidente Kennedy (ES). }\end{array}$ \\
\hline $\begin{array}{l}\text { Caminhada na Feira } \\
\text { Livre do Produtor } \\
\text { Rural de Viçosa, } \\
\text { realizada em abril de } \\
2012 \text {, no Município de } \\
\text { Viçosa. }\end{array}$ & $\begin{array}{l}\text { Nessa manifestação houve entrega de panfletos informando } \\
\text { sobre os impactos ocasionados pelo o mineroduto. Além } \\
\text { disso, as organizações como o MAB, MST, PACAB e Levante } \\
\text { Popular da Juventude estavam tirando as dúvidas da } \\
\text { população sobre o mineroduto. Contando também com } \\
\text { várias faixas, chamando a atenção da população para o } \\
\text { descontentamento da implantação do empreendimento no } \\
\text { município. }\end{array}$ \\
\hline $\begin{array}{l}\text { Reuniões com as } \\
\text { comunidades } \\
\text { atingidas pelo o } \\
\text { mineroduto da } \\
\text { Ferrous em Viçosa, } \\
\text { Paula Cândido, } \\
\text { Ervália, e Coimbra, } \\
\text { realizada entre os } \\
\text { meses de fevereiro a } \\
\text { abril de 2012. }\end{array}$ & $\begin{array}{l}\text { As reuniões tiveram o intento de levar informações sobre o } \\
\text { mineroduto da Ferrous para as comunidades atingidas pelo } \\
\text { empreendimento, bem como retirar as dúvidas sobre o } \\
\text { empreendimento. }\end{array}$ \\
\hline $\begin{array}{l}\text { Assembleia Popular } \\
\text { na Câmara de } \\
\text { Vereadores de Viçosa, }\end{array}$ & $\begin{array}{l}\text { Essa assembleia teve o propósito de explanar para a } \\
\text { comunidade Viçosense sobre o projeto do mineroduto da } \\
\text { Ferrous e os principais impactos socioambientais que }\end{array}$ \\
\hline
\end{tabular}


grandes...

\begin{tabular}{|l|l|}
\hline realizada em abril de & ocasionará no município de Viçosa. Na assembleia, foi \\
Viçosa. & enfatizado o problema de abastecimento de água que Viçosa \\
vem enfrentando, e que o mineroduto irá passar nas & nascentes do ribeirão São Bartolomeu, principal ribeirão que \\
abastece o município. Explicando, assim, que o mineroduto \\
irá afetar o abastecimento de água do município \\
futuramente. Houve, também, a discussão sobre como está \\
acontecendo o processo de indenização e o valor pago para \\
a desapropriação da terra para o mineroduto passar. Após a \\
assembleia, em frente à Câmara, houve batuque e gritos de \\
ordem, demonstrando a insatisfação pela implantação do \\
empreendimento no município.
\end{tabular}

Fonte: Dados da pesquisa, 2012.

Após essas manifestações, outras entidades (AGB, NACAB e Associação dos Moradores do Bairro Santa Clara) começaram a se articular, constituindo, então, a "Campanha pelas Águas e Contra o Mineroduto da Ferrous".

A campanha é em nome de um grupo de pessoas, composto por atingidos e representantes dos movimentos sociais, e tem por objetivo, como dito anteriormente, criar espaços para discutir e informar os atingidos e a comunidade em geral sobre os possíveis impactos causados não só junto aos atingidos, mas também junto ao estoque de água do Município de Viçosa.

É importante ressaltar que esse processo de cooperação desencadeado contra o mineroduto contribuiu para que a campanha fosse levada às ruas, informando e alertando da problemática que Viçosa está vivenciando.

Assim, a campanha organizou uma passeata contra o mineroduto da Ferrous e em defesa das águas, que foi realizada em maio de 2012, no Município de Viçosa. Essa passeata teve o propósito de manifestar a insatisfação pela implantação do projeto do mineroduto da Ferrous, no Município de Viçosa, para a comunidade Viçosense, para o Estado e para a empresa Ferrous.

A manifestação teve início na Feira Livre do Produtor Rural com destino à Praça Silviano Brandão, centro de Viçosa. Batucada pelas ruas e palavras de ordem, com auxílio de faixas, tambores e megafone 
chamaram a atenção da comunidade Viçosense sobre o abastecimento de água no município e a implantação do mineroduto.

Figura 2. Passeata contra o Mineroduto da Ferrous e em defesa das Águas, Viçosa, 2012

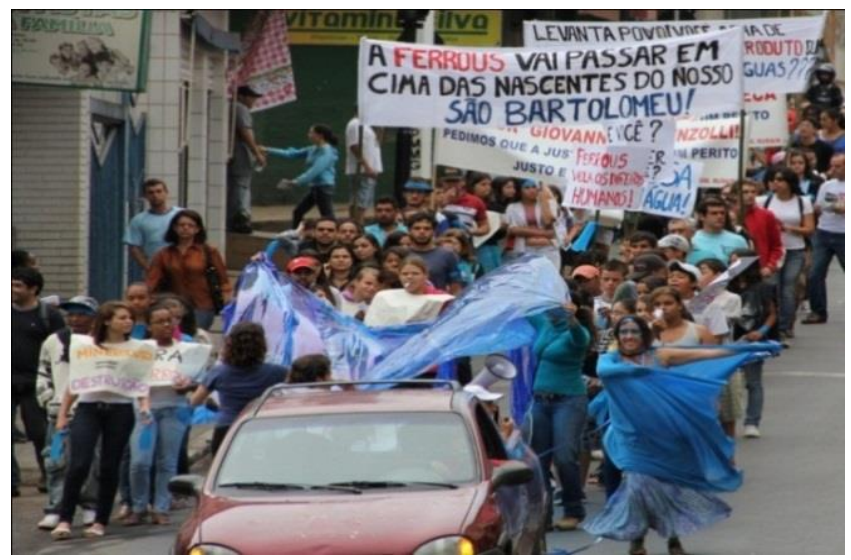

Fonte: Foto dos autores, 2012.

Com o intuito de melhorar a comunicação com esse grupo organizado e disseminar as informações sobre o mineroduto, foi criado o blog "campanha pelas águas". Dessa forma, as notícias publicadas no blog ganharam discussões nas redes sociais, principalmente, no Facebook.

Como resultado dessa marcha e das denúncias do projeto do mineroduto realizadas para o promotor de justiça da Comarca de Viçosa, houve uma Audiência Pública promovida pelo MPMG, que foi realizada no dia 12 de julho de 2012, no Município de Viçosa. Na ocasião, vários atingidos relataram os impactos e a violação dos direitos humanos que vêm enfrentando com a implantação do mineroduto da Ferrous. Na audiência, o promotor explanou que:

a Ferrous apresentou um laudo sobre a instalação do mineroduto, o qual foi comparado com a perícia feita pela CEAT, e várias incongruências foram observadas. Uma delas diz respeito ao consumo humano de água. De acordo com a Ferrous Ressources, não há consumo na jusante dos cursos que serão atravessados pelo mineroduto, informação que não corresponde à perícia feita pela CEAT" (RELATO DA AUDIÊNCIA PÚBLICA PROMOVIDA PELO MPMG, 2012). 
Após dois meses da audiência, foi realizada uma entrevista com o promotor. Ele relatou que, até o momento, não teve uma mediação entre o ministério público e o empreendedor, pois ele acredita que:

a mediação pelo Ministério Público poderia ser alcançada a partir da celebração de um termo de ajustamento de conduta, onde a empresa se comprometesse, desde que identificasse as irregularidades, a regularizar essa questões pra instalação ou não da sua obra do mineroduto aqui no município (RELATO DO PROMOTOR DA JUSTIÇA DE VIÇOSA, 2012).

Por fim, no início de junho de 2013 , o promotor encaminhou uma carta ao representante do PACAB informando que o processo com a Ferrous tinha sido arquivado e construído um Termo de Ajustamento de Conduta-TAC. Esse termo explana que, antes da Ferrous iniciar a construção do mineroduto, a empresa tem que fazer um estudo hídrico no Município de Viçosa.

Outra manifestação realizada foi a assembleia popular, em outubro de 2012, no Município de Paula Cândido. O objetivo dessa audiência foi reunir a população do Município de Paula Cândido e de outros municípios para discutir os impactos sociais e ambientais do empreendimento e pensar alternativas de resistência. Após ampla discussão dos problemas do mineroduto, foi encaminhada uma ação coletiva de Paula Cândido contra a passagem de tal empreendimento e a solicitação de estudos para averiguar os impactos nos recursos hídricos do município. A assembleia popular deliberou pela continuidade da campanha nesse município.

Atualmente, a campanha está desenvolvendo três núcleos no trajeto do mineroduto, localizados nos municípios de Viçosa, Conselheiro Lafaiete e Muriaé. Esses núcleos têm o objetivo de desenvolver o trabalho da campanha em outros locais afetados pelo empreendimento. Dessa forma, a campanha conseguirá articular com a maioria dos atingidos que estão no trajeto do empreendimento.

Apesar da Ferrous ter afirmado que a execução do projeto do mineroduto será para 2016, o representante da campanha declara que vai seguir firme e convoca toda a população para continuar se organizando, empenhando-se e pressionando os outros atores 
envolvidos no processo, impedindo que a multinacional deixe para nosso país um rastro de destruição ambiental e social (BLOG CAMPANHA PELAS ÁGUAS E CONTRA O MINERODUTO DA FERROUS, 2013).

Outro desencadeamento do processo de cooperação foi o encaminhamento da constituição da "Associação dos Atingidos pelo Mineroduto da Ferrous". Essa ideia surgiu na reunião da comunidade rural de Coimbra, juntamente com os atingidos do Município de Viçosa, Ervália, Cajuri e Paula Cândido.

Após essa reunião, os atingidos do Município de Coimbra continuaram com as suas reuniões para discutir assuntos referentes ao mineroduto, sendo um deles o processo de constituição da "Associação dos Atingidos pelo Mineroduto da Ferrous do Município de Coimbra e Região". Essa, como dito anteriormente, teria o propósito de cobrar e reavaliar o valor das indenizações propostas pela a Ferrous no Município de Coimbra e região.

Porém, a principal dificuldade que estava sendo encontrada pelos atingidos para constituir a associação é que as pessoas que estavam participando desse grupo não tinham tempo para se dedicar e resolver os problemas da associação. Assim, outra opção que o grupo via era articular com os atingidos dos outros municípios que estão no trajeto do mineroduto e constituir a associação. Dessa forma, poderiam ser encontradas pessoas que tivessem tempo para dedicar aos trabalhos necessários.

Nessa perspectiva, na audiência pública promovida pelo MPMG, no Município de Viçosa, os atingidos de Coimbra convidaram os atingidos de outros municípios presentes para constituir a "Associação dos Atingidos pelo Mineroduto da Ferrous". Essa associação contemplaria todos os municípios que estão no trajeto de tal empreendimento e não só os de Coimbra e região, como era a ideia inicial da associação. A formalização desse grupo de atingidos seria importante para entrar judicialmente com uma ação civil coletiva de indenização.

Segundo Augusto (2009), para entrar com tal ação é necessário que se tenha uma associação que represente o interesse do coletivo, estipulado no seu estatuto, e que a mesma tenha uma "pré-constituição há mais de um ano e para os órgãos públicos exige-se a pertinência temática". 
Em termos práticos, a ação civil coletiva possibilita que os atingidos consigam que o Ministério Público disponibilize ou contrate um técnico perito em avaliações de imóveis rurais para realizar a reavaliação do valor das indenizações. Isso acontecendo, a Ferrous fica obrigada a pagar o valor apurado pelo técnico. Por exemplo: se o empreendedor tinha pagado $\mathrm{R} \$ 30.000,00$ para um proprietário e o técnico determina que a propriedade vale $R \$ 70.000,00$, o empreendedor tem que pagar a diferença, isto é, pagar mais $R \$$ 40.000,00 para o proprietário atingido.

Além disso, essa associação poderia entrar também com uma ação coletiva em defesa dos recursos hídricos, uma vez que os outros municípios atingidos também sofrerão com o problema de desabastecimento de água, já que o mineroduto passará em cima das nascentes dos outros municípios.

Tendo em vista esse cenário, é de extrema importância que os atingidos constituam tal associação, que ainda não saiu do papel. Mas existe uma articulação dos atingidos para que ela possa ser constituída. É relevante ressaltar que, apesar de a campanha ser um grupo consolidado, formado por atingidos de vários municípios, ela não pode entrar com uma ação civil coletiva de indenização, pois ela não é pessoa jurídica, isto é, não possui CNPJ para entrar com ação coletiva na justiça.

Em termos práticos, as associações são fundamentais para a sociedade civil. Elas operam para captar recursos, acessar políticas públicas, defender os direitos das pessoas e resistir ao estabelecimento de condições que desafiam a humanidade, como as questões referentes ao meio ambiente e ao desenvolvimento sustentável.

\section{CONSIDERAÇÕES FINAIS}

A pesquisa revelou que o processo de cooperação como ferramenta de organização de grupos atingidos por empreendimentos de infraestrutura pode ser desencadeado por um cenário de conflitos ambientais, gerando resultados positivos.

No caso estudado, pode-se dizer que as ferramentas de organização utilizadas pelos grupos atingidos foram as reuniões, a constituição da "Campanha pelas Águas e Contra o Mineroduto da 
Ferrous" e o processo de constituição da Associação dos Atingidos pelo Mineroduto da Ferrous.

O processo de cooperação, no caso, envolveu os atingidos pelo mineroduto da Ferrous e os representantes das entidades MAB, PACAB, ENEBio, NACAB, MST, AGB, Levante Popular da Juventude, Associação dos Moradores do Bairro Santa Clara, Associação dos Moradores do Bairro Palmital, Paróquia Nossa Senhora de Fátima de Viçosa e estudantes da UFV. A ação coletiva desses atores foi de extrema importância para as comunidades atingidas perceberem que "juntos somos mais fortes" (RELATO REPRESENTANTE DA COMUNIDADE RURAL DE COIMBRA, 2012), isto é, com a força de todos o mineroduto pode não ser construído.

Nesse sentido, percebe-se que foi a partir da cooperação desses atores sociais que denúncias sobre os impactos do mineroduto foram formalizadas, tanto nas audiências públicas quanto nas reuniões da Câmara de Vereadores.

Os grupos também produziram diversas outras ações: manifestações de resistência contra a implantação do mineroduto, criação da "Campanha pelas águas e contra o mineroduto da Ferrous" a fim de disseminar informações para a sociedade sobre tal empreendimento nos meios midiáticos e articular a constituição da "Associação dos Atingidos pelo Mineroduto da Ferrous". De acordo com o referencial teórico deste trabalho, tal associação será de reivindicação.

Além disso, a associação é crucial para que os atingidos entrem com uma ação civil coletiva de indenização e uma ação coletiva em defesa dos recursos hídricos nos municípios que serão atingidos pelo mineroduto. Para entrar com tal ação, é necessário que se tenha uma associação que represente o interesse do coletivo, estipulado no seu estatuto, e que a mesma tenha um ano de funcionamento. Apesar de a campanha ser um grupo consolidado, formado por atingidos de vários municípios, ela não pode entrar com uma ação civil coletiva de indenização, pois não é pessoa jurídica, isto é, não possui CNPJ para entrar com ação coletiva na justiça.

Logo, é importante enfatizar que os atingidos, juntamente com os representantes das entidades que compõe a campanha, utilizaram a cooperação como ferramenta para se organizar, tendo como principal 
objetivo comum o impedimento da construção do mineroduto, que está trazendo e trará diversos impactos negativos para as comunidades. Mas, caso isto não aconteça, os atingidos querem que alguns impactos sejam eliminados, dentre eles: que o valor das indenizações passe por uma reavaliação, bem como, que o mineroduto não passe nas nascentes, mudando o seu trajeto.

Assim, este estudo permitiu demonstrar que o resultado da cooperação demonstrou para o Estado (por meio da Promotoria de Justiça da Comarca de Viçosa, do Ministério Público do Estado de Minas Gerais e da Procuradoria Federal) e para a sociedade como o empreendedor considera os atingidos diante do desenvolvimento dos seus projetos. Além de reunir informações e reflexões para a população da região sobre os impactos de tais obras nos municípios atingidos.

\section{REFERÊNCIAS}

ASSOCIAÇÃO DOS GEOGRÁFOS BRASILEIROS. Relatório sobre os Impactos Socioambientais do Mineroduto da Ferrous na microrregião de Viçosa-MG - Seção Local Viçosa. UFV, Minas Gerais, 2012.

AUGUSTO, Ana Lúcia Creão. Condições da ação na defesa de direitos difusos e coletivos. 2009. Disponível em: < jus.com.br/revista/texto/17953/condicoes-da-acao-na-defesa-dedireitos-difusos-e-coletivos >. Acesso em 06 mar. 2013.

BLOG CAMPANHA PELAS ÁGUAS E CONTRA O MINERODUTO DA FERROUS. 2013: Um ano decisivo para as comunidades atingidas. Disponível em: <http://campanhapelasaguas.blogspot.com.br/>. Acesso em 01 mar. 2013.

BRANDT Meio Ambiente. Relatório de Impactos Ambientais: Mineroduto Ferrous Minas Gerais, Rio de Janeiro e Espírito Santo. 2010.

BRONZ, Deborah. Empreendimentos e empreendedores: formas de gestão, classificações e conflitos a partir do licenciamento ambiental. Tese (Doutorado em Antropologia Social) - Universidade Federal do Rio de Janeiro, Museu Nacional, Rio de Janeiro, 2011. 
DEFOURNY, Jacques. Vers une économic politique des associations. In: Congrès des Economistes Belges de Langue Française, 10e. Les fonctions collectives dans une économie de marché. V.4. Vie associative et fonctions collectives. Charleroi:CIFOP, 1992. p.37-68.

DICIONÁRIO DE CIÊNCIAS SOCIAIS. 2.ed. Rio de Janeiro: FGV/MEC, 1987.

FONSECA, Bruno Costa; OLIVEIRA, Marcelo Leles Romarco de; SOUSA, Dayane Rouse Neves. Conflitos Ambientais: atores, causas e desdobramentos na Zona da Mata Mineira. Caminhos de Geografia, Uberlândia, v.13, no42, 2012. p.283-299.

FRANTZ, Walter. Educação e cooperação: práticas que se relacionam. Sociologias, Porto Alegre, ano $3, n^{\circ} 6$, jul/dez 200. p.242-264.

JORNAL FOLHA DA MATA. Desapropriados e autoridades discutem revisão dos valores de indenizações do Mineroduto. Viçosa, p.11, 24 de jun. 2011.

JORNAL FOLHA DA MATA. Assembleia Popular "Água x Mineroduto" em Viçosa. Viçosa, p.10, 26 de abr. 2012.

JORNAL TRIBUNA LIVRE. Ferrous garante que mineroduto não atingirá nascentes. Viçosa, p.5, 24 de mai. 2012.

MINAS GERAIS. Decreto $s / n$ de utilidade pública, 13 de julho de 2009. Disponível em: <http://www.jusbrasil.com.br/diarios/7515819/doemgexecutivo-14-07-2009-pg-2>. Acesso em 10 jan. 2013.

RING, Peter Smith; VAN DE VEN, Andrew H. Developmental Processes of Cooperative Interorganizational Relationships. Academy of Management Review, New York, v. 19, n. 1,1994. p. 90-118

VALADARES, José Horta. Notas de aula da disciplina ERU 170 Introdução ao Cooperativismo. Universidade Federal de Viçosa: Viçosa. 2009. 
VENTURA, Magda Maria. O Estudo de Caso como Modalidade de Pesquisa. Disponível em: $<$ http://sociedades.cardiol.br/socerj/revista/2007_05/a2007_v20_n05_ art10.pdf $>$. Acesso em 30 jul. 2012.

WAUTIER, Anne Marie. A construção identitária e o trabalho nas organizações associativas. Itujuí: Unijuí, 2001.

ZHOURI, Adréia; ROTHMAN, Franklin Daniel. Assessoria aos atingidos por barragens em Minas Gerais: desafios, limites e potencial. In: Franklin Rothman (org.), Vidas alagadas: conflitos socioambientais, licenciamento e barragens, Viçosa: UFV, 2008.

Submetido em $02 / 10 / 2013$

Aprovado em 07/06/2015 


\section{Sobre os autores}

Dayane Rouse Neves Sousa

Bacharela em Cooperativismo pela Universidade Federal de Viçosa e Mestranda em Extensão Rural pela mesma instituição. Membra do Grupo de Pesquisa em Conflitos Ambientais, Agricultura e Sociedade.

E-mail: sousadayane@ymail.com

\section{Marcelo Leles Romarco de Oliveira}

Bacharel em Administração pela Universidade Federal de Lavras. Especialista em História do Brasil Pós-1930. Mestre em Extensão Rural pela Universidade Federal de Viçosa. Doutor em Ciências Sociais pela Universidade Federal Rural do Rio de Janeiro. Professor Adjunto I do Departamento de Economia Rural da Universidade Federal de Viçosa e Coordenador do Grupo de Pesquisa em Conflitos Ambientais, Agricultura e Sociedade.

E-mail: mlromarco@yahoo.com.br 